\title{
Competition, Innovation, and the Number of Firms ${ }^{\dagger}$
}

\author{
Pedro Bento \\ Texas A\&M University*
}

March 2016

Abstract

I look at manufacturing firms across countries and over time, and find that barriers to competition actually increase the number of firms. This finding contradicts a central feature of all current models of endogenous markups and free entry, that higher barriers should reduce competition and firm entry, thereby increasing markups. To rationalize this finding, I extend a standard model in two ways. First, I allow for multi-product firms. Second, I model barriers as increasing the cost of entering a product market, rather than the cost of forming a firm. Higher barriers to competition reduce the number of products per firm and per market, but increase markups and the total number of firms. Calibrating the model to U.S. data, I estimate cross-country differences in consumption as large as 65 percent from observed differences in barriers to competition. In addition, increasing barriers generates either a negative or inverted$\mathrm{U}$ relationship between firm-level innovation and markups. While higher markups encourage product-level innovation through the usual Schumpeterian mechanism, firm-level innovation (at least eventually) drops as firms reduce their number of products. I provide new evidence supporting these two novel implications of the model - that product-level innovation increases with barriers to competition, while the number of products per firm decreases.

Keywords: product market regulation, entry costs, firm size, productivity, innovation, markups, competition, multi-product firms, innovation, inverted-U.

JEL codes: L1, L5, O1, O3, O4.

\footnotetext{
${ }^{\dagger}$ I would like to thank Olivier Coibion, Gueorgui Kambourov, Huiyu Li, Gabriel Ulyssea, Xiaodong Zhu, and seminar participants at George Washington University and the University of Texas at Austin for helpful comments and suggestions. All remaining errors are my own.

${ }^{*}$ Texas A\&M University, Department of Economics, 3056 Allen Building, 4228 TAMU, College Station, TX 77843. E-mail: pbento@tamu.edu.
} 


\section{Introduction}

There is now an abundance of empirical evidence that more competition (i.e., lower markups) and lower barriers to competition are associated with more firm-level innovation and higher aggregate productivity. ${ }^{1}$ Current models with free entry and endogenous markups connect markups to the number of firms through Bertrand competition (Bento, 2014; Peters, 2015), Cournot competition (Edmond, Midrigan, and Xu, 2015), Lancaster preferences (Desmet and Parente, 2010), and linear demand (Melitz and Ottaviano, 2008). Some of these models address the question of innovation, some do not. But a common feature across all of these models is that barriers to competition should reduce the number of firms. Higher barriers increase the cost of entry, which lowers the value of entry, which in turn results in less entry and fewer firms. This consequence of high barriers is unambiguous, straightforward, and very intuitive. It is also, apparently, wrong.

Figure 1 shows how the number of firms per worker in a country's manufacturing sector varies with the level of product market regulation in a cross-section of 44 countries. These data, which I describe later in more detail, are from Bento and Restuccia (2015) and the OECD's Indicators of Product Market Regulation (PMR). In contrast to the predictions of current models, Figure 1 shows very clearly that countries with high barriers to competition have far more firms. For example India, which has the highest measured barriers in the sample, has about seven times as many firms per worker as the U.S. This is not just a cross-country phenomenon. Using panel data from a number of European Union members, I show that the implementation of the Single Market Programme (SMP), which lowered barriers to competition in certain industries in the early 1990s, led to a subsequent drop in the number of firms in affected industries, relative to industries and countries that were unaffected by the SMP. ${ }^{2}$ This contrast with theory is particularly puzzling because other predictions of the models seem to hold up empirically.

\footnotetext{
${ }^{1}$ For example, see Nickel (1996), Blundell, Griffith, and Van Reenen (1999), Nicoletti and Scarpetta (2003), Aghion, Braun, and Fedderke (2008), and Griffith, Harrison, and Simpson (2010).

${ }^{2}$ The SMP resulted in low barriers to competition in most industries. The most affected industries were those with initially high barriers.
} 


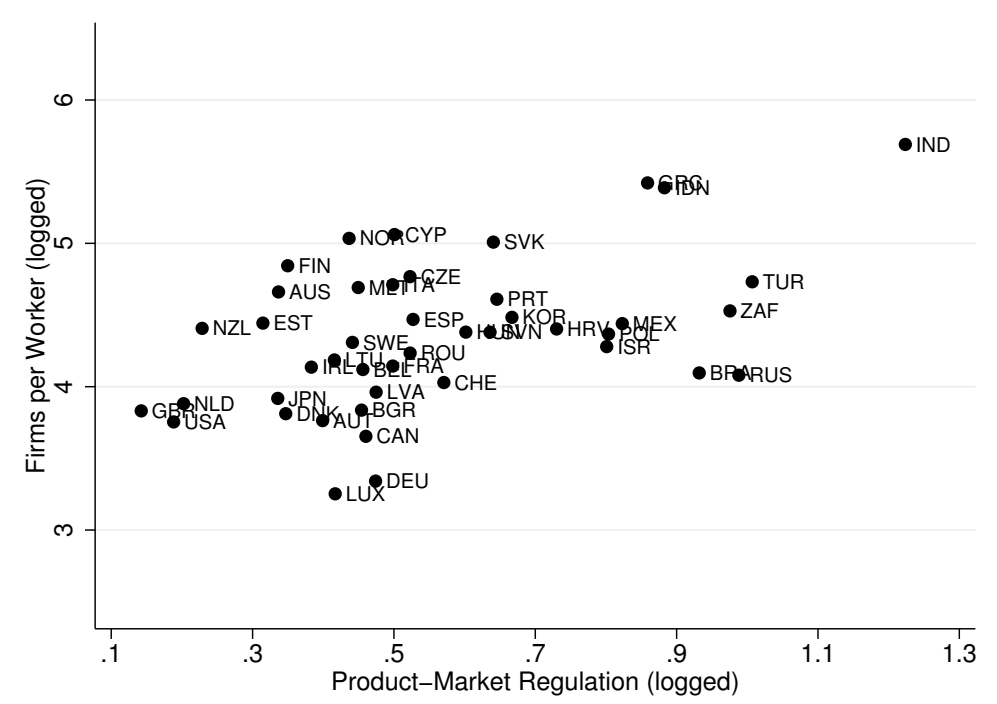

Figure 1: Product-Market Regulation and the Number of Firms

Bento (2014), in particular, shows how barriers to competition can in theory simultaneously increase markups and decrease firm-level innovation. But as with all other models, barriers are still predicted to reduce the number of firms.

In this paper I show that all of these empirical phenomena can be rationalized by extending a standard model of endogenous markups and free entry in two very simple ways. First, I allow for multi-product firms. This breaks the link between the number of firms present in an industry and the number of firms competing in each product market. Second, I model barriers to competition as barriers to entry into a product market, rather than barriers to firm formation. I keep the model as simple as possible to highlight the central mechanism. Potential firms choose whether or not to become producers, how many product markets to enter, and how much to invest in the quality of each product. Then firms in each product market compete through Cournot competition with differentiated products. I compare equilibria with different fixed costs of entering a product market, and find that high entry costs reduce the number of products per firm. For a given number of firms this must reduce competition within each product market, which results in higher markups. These higher markups increase both the value of forming a firm and the incentive to invest in the quality of each product (the usual 
Schumpeterian mechanism). As a result, both product-level quality and the number of firms increases. While product-level quality increases, however, the number of products per firms is lower. The net effect on firm-level quality investment depends on parameter values. If the elasticity of product quality with respect to investment is relatively high, then higher barriers unambiguously reduce firm-level investment. If the elasticity is high, then barriers and firmlevel investment exhibit an inverted-U relationship. When barriers start low, higher barriers increase firm-level investment. But after some threshold, any further increase in entry barriers reduces firm-level investment. In line with the evidence in Aghion, Braun, and Fedderke (2008), however, aggregate investment in quality is always reduced when entry barriers increase.

The model developed in this paper is quite parsimonious, and can easily be taken to the data. By calibrating the model to match relevant features of the U.S. manufacturing sector, as well as the empirical relationship between the number of firms and the OECD's measure of barriers to competition, I show how the model can be used to predict the quantitative impact of entry barriers on aggregate outcomes. The impact is substantial. An increase in barriers large enough to increase the OECD's measure from that of the U.S. to that of Greece (which lies in the middle of the sample) generates a decrease in consumption of 42 percent.

In addition to rationalizing previous empirical findings, the model generates two other testable implications. First, countries with higher average markups should have fewer products per firm. Using firm-level survey data from the World Bank's Enterprise Surveys, I present evidence suggesting exactly this. Second, higher barriers to competition should be associated with higher product-level quality, notwithstanding the negative empirical relationship between barriers and firm-level innovation confirmed in many studies. I test this indirectly by comparing the average number of citations per patent applied for in the U.S. across the countries present in the OECD's PMR dataset. Citations have become a widely-used measure of patent quality. Once relevant variables are controlled for, I find that patents originating in countries with higher entry barriers are indeed of higher quality. To my knowledge, this is the first paper to present evidence about 
the relationship between barriers to competition, the number of products per firm, and patent quality. Aghion et al. (2005), for example, present evidence of an inverted-U relationship between markups and firm-level innovation (measured as the total number of citation-weighted patents generated by a firm), but do not consider the number of citations per patent.

The model is a very standard one of free entry and endogenous markups, a simple static version of Melitz (2003) but with a finite number of competing firms within each product market, and extended to allow for multi-product firms as in Bernard, Redding, and Schott (2010). I hasten to emphasize that none of the separate features of the model are new. The contribution of the model is to show how incorporating all of these features allows me to rationalize several empirical phenomena related to entry barriers and competition, and to quantify the impact of observed differences in entry barriers. All current models with free entry and endogenous markups can generate the empirical link between markups and barriers to entry. Only one model (Bento, 2014), to my knowledge, has been able to generate a negative relationship between entry barriers and firm-level innovation. ${ }^{3}$ But Bento's (2014) model is somewhat stylized and difficult to take to the data. And of course, it has the inconvenient implication that barriers to entry must decrease the number of firms. Developing a model with free entry that predicts higher firm-level innovation when barriers to competition are reduced has proven to be difficult (see Holmes and Schmitz (2010) for a discussion of this point), as the lower markups that result from higher firm entry should result in lower incentives to innovate - a point made by Schumpeter (1942). The model developed here offers a simple, very intuitive explanation for the empirical relationship between competition and firm-level innovation. The Schumpeterian mechanism still holds at the product level, so that higher barriers to competition increase product-level quality, but the lower number of products per firm induced by higher barriers drag down firmlevel quality investment and result in either an inverted- $U$ or negative relationship between markups and firm-level innovation.

\footnotetext{
${ }^{3}$ I am neglecting models without free entry, for obvious reasons. See Holmes and Schmitz (2010) for a discussion of the difficulty of generating a negative relationship between entry barriers and firm-level innovation in a model with free entry.
} 
Although in this paper barriers to competition are interpreted as barriers to product market entry, they could just as easily be interpreted as barriers to entry into geographical markets. As such, the results of the model developed in this paper are consistent with the U.S. experience with barriers (and the reduction of barriers) to branch banking. Carlson and James (2006) document evidence of how the easing of restrictions on branch banking resulted in more (and on average, less productive) bank branches, more competition between branches, and fewer banks, all consistent with the results of this paper.

There is a long tradition in the antitrust literature (both in and outside of economics) of drawing a distinction between the number of firms in an industry and the number of firms competing in a market. ${ }^{4}$ This paper contributes to this literature by analyzing how entry barriers can have opposite effects on the number of firms and the level of competition within a market.

By analyzing the effects of entry barriers on the number of firms, both empirically and in theory, this paper contributes to the growing literature attempting to explain differences in firm size (the inverse of the number of firms per worker) across countries. See, for example, Bhattacharya, Guner, and Ventura (2013), Hsieh and Klenow (2014), and Bento and Restuccia (2015).

In the next section I describe the data used to produce Figure 1 and show that the positive relationship between entry barriers and the number of firms is robust to including various controls. I provide further evidence of this relationship by analyzing the impact of the Single Market Programme on affected country-industries. In Section 3 I describe the model, characterize equilibrium, and discuss its key implications. I calibrate the model in Section 4 and quantify the impact of observed entry barriers. In Section 5 I describe the data used to test the relationships between markups and products per firm, and between entry barriers and product quality, and show that the data is consistent with the implications of the model. The final section concludes.

\footnotetext{
${ }^{4}$ In economics, see for example Stigler and Sherwin (1985), who propose a method for market delineation based on price data.
} 


\section{Barriers to Competition and the Number of Firms}

Here I provide evidence from both cross-country and panel data that barriers to competition increase the number of firms. I begin with the cross-country evidence.

\subsection{Across Countries}

I provide details about the data illustrated in Figure 1 and show that the relationship between barriers to competition and the number of firms is robust to controlling for other country-specific characteristics that could affect the number of firms. My measure of barriers to competition is from the OECD's Indicators of Product Market Regulation (PMR). The PMR database reports an economy-wide index of how restrictive regulations are for competition for 47 countries, 34 of them OECD and 13 non-OECD. The PMR index is constructed using answers to over 700 survey questions asked of government officials in each country. The final index value given to each country can range from 0 to 6 , with a higher value indicating a regulatory environment more restrictive to competition. The database contains measures of PMR for as many as four years between 1998 and 2013 for OECD countries and as many as two years (2008 and 2013) for non-OECD countries. Given the lack of data for non-OECD countries before 2008, I use each country's 2008 value when available, and its 2013 value otherwise. More details about the construction of the dataset are provided in Koske et al. (2015).

Data on the number of firms across countries is from Bento and Restuccia (2015), who use hundreds of census reports, business registries, and reports on representative surveys to construct a standardized measure of average establishment size in manufacturing, defined as the number of persons engaged per establishment, for 134 countries. My measure of the number of firms per worker is the inverse of the measure used in Bento and Restuccia (BR), multiplied by 1000. Of the 134 countries in the BR data, 44 are included in the PMR database. 
Of course other country-specific characteristics besides barriers to competition could affect the number of firms. ${ }^{5}$ To control for these other factors, I use data from the World Bank's Doing Business project. Doing Business reports both the monetary cost and time involved in dealing with a host of regulations that impact the running of a business (and therefore, presumably, the incentive to start a firm). For each variable covered, an overall measure is constructed of how stifling are the relevant regulations. I use the value of this overall measure for the ease of setting up a limited liability company, securing a construction permit, registering a commercial property, obtaining an electricity connection, obtaining credit, complying with tax regulations, engaging in international trade, enforcing contracts, resolving insolvency, and protecting the rights of minority shareholders. ${ }^{6}$

Table 1: Product Market Regulation And the Number of Firms

\begin{tabular}{llll}
\hline dependent variable: & \multicolumn{3}{c}{ number of firms } \\
\hline PMR & $1.00^{* * *}$ & $0.95^{* *}$ & $0.92^{* *}$ \\
& $(0.29)$ & $(0.44)$ & $(0.39)$ \\
& & & \\
controls included & no & yes & yes \\
outliers included & yes & yes & no \\
\hline$R^{2}$ & 0.25 & 0.44 & 0.39 \\
observations & 44 & 44 & 41 \\
\hline
\end{tabular}

Notes: PMR is from the OECD's Indicators of Product Market Regulation, and number of firms per worker is from Bento and Restuccia (2015). All controls are from the World Bank's Doing Business dataset. All variables are logged, and robust standard errors are in parentheses. ${ }^{* *}$ and ${ }^{* *}$ refer to one and five percent levels of significance.

The first column of Table 1 shows the results of an OLS regression of the (logged) number of firms in each country on each country's (logged) PMR Index value. The point estimate is statistically significant and suggests an increase in PMR of one percent is associated with a one percent increase in the number of firms. The second column shows that this estimate is

\footnotetext{
${ }^{5}$ For example, Bento and Restuccia (2015) argue that policies and institutions which cause a misallocation of factor inputs across firms can lead to a greater number of firms.

${ }^{6}$ The Doing Business scores range from 0 to 100 . Because I use logged variables in the regressions below, I replace 0 with 0.1 in 31 cases. Values for 2006 are used when available. Otherwise, the earliest available year after 2006 is used. See doingbusiness.org for more details about the data and methodology.
} 
only marginally lower (and still significant at the 5 percent level) when the ten variables from Doing Business are included in the regression. To ensure these results are not being driven by outliers, the third column reports the results of an OLS regression with India (which has the highest PMR score in the sample), Luxembourg (which has the lowest number of firms in the sample), and Germany (similarly low number of firms) excluded. Although not shown here, both the level of significance and the point estimate on PMR are marginally higher when only India is excluded. Also, significance levels are marginally higher when variables are not logged.

\section{$2.2 \quad$ A Natural Experiment}

Despite the large number of controls included in the regressions of the previous section, the possibility always remains that omitted variables are driving the observed relationship between barriers to competition and the number of firms. To address this, I study a particular episode of product market deregulation. The Single Market Programme (SMP) was a large-scale program that set out to reduce non-tariff barriers to trade between E.U. members and reduce barriers to competition. All reforms were intended to be implemented by 1992. Many were not, but Notaro (2002) reports that $93 \%$ of all SMP reforms had been implemented by 1996 . What makes this a particularly appealing episode to study is that the SMP was intended to reduce barriers to competition to a common low level across industries in all E.U. countries. As a result, the effects of the SMP were expected to vary across industries depending on the initial level of barriers and across countries depending on how important each industry was ex-ante relative to each country's manufacturing sector. This allows me to use exogenous variation in the magnitude of reforms across industries and in the importance of affected industries across countries to identify the impact of the SMP on the number of firms within a country-industry. This episode has been exploited in several studies to identify the effects of barriers to competition on markups (for example, Griffith, Harrison, and Simpson, 2010) and on firm-level innovation (Aghion et al., 2005). For more details, see Griffith, Harrison, and Simpson for an excellent summary of 
the Single Market Programme and the characteristics of the SMP that make it an appropriate episode for this type of analysis.

To identify industries within each country that were expected to be affected by the reforms, I follow Griffith, Harrison, and Simpson (2010) in using the industry-level classifications in a European Commission report by d Potentially affected industries fall into four groups: SMP1, characterized as "high-technology public procurement" industries; SMP2 and SMP3, "traditional public-procurement and regulated markets" with high and low price dispersion (respectively); and SMP4, industries with moderate barriers to competition. Buigues, Ilzkovitz, and Lebrun remove a country-industriy from a group if it uniquely faces lower barriers to competition than the same industry in other countries. As a measure of each affected industry's importance to each economy, I use each industry's employment share in manufacturing in 1986-87, also from Buigues, Ilzkovitz, and Lebrun (Table 26). ${ }^{7}$

The firm count data I use for this analysis is from Eurostat's Structural Business Statistics. Measures of the number of firms and the number of persons engaged by 2-digit industry are available for Denmark, France, and Portugal from 1990 to 2000. To control for differences in the size of each industry over time and across countries, I use the ratio of firms to persons engaged as my measure of the number of firms. Eurostat also reports firm counts for three non-E.U. countries, Finland, Japan, and Sweden, and I include these countries to help control for non-SMP sources of variation in the number of firms over time.

The equation I estimate is;

$$
y_{c, i, t}=\alpha+\sum_{t \in T} \delta_{t}^{T}+\sum_{c \in C} \sum_{i \in I} \delta_{c, i}^{C I}+\beta_{1} \mathrm{SMP} 1_{c, i, t}+\beta_{2} \mathrm{SMP} 2_{c, i, t}+\beta_{3} \mathrm{SMP} 3_{c, i, t}+\beta_{4} \mathrm{SMP} 4_{c, i, t}+\epsilon_{c, i, t},
$$

where $y_{c, i, t}$ denotes the (logged) number of firms in a country-industry-year, $\delta^{T}$ is a fixed time effect, and $\delta^{C I}$ is a fixed country-industry effect. $\mathrm{SMPk}, \mathrm{k} \in\{1,2,3,4\}$, is equal to zero

\footnotetext{
${ }^{7}$ Buigues, Ilzkovitz, and Lebrun (1990) report employment shares for affected 3-digit industries. I adjust these shares to account for the higher level of aggregation in my data, described below.
} 
for unaffected country-industry-years, and equal to the share of employment in manufacturing accounted for by a country-industry in 1986-87 for an affected country-industry that falls within category SMPk on or after 1992. The firm count data for each country excludes firms with less than some threshold number of workers, and this threshold is not constant across countries, so I include fixed country-industry effects to account for this difference. As a result, the inclusion of non-SMP countries helps to identify fixed time effects but not industry-specific effects.

Table 2: SMP AND the Number OF Firms

\begin{tabular}{lllll}
\hline dependent variable: & \multicolumn{4}{c}{ number of firms } \\
& $(1)$ & $(2)$ & $(3)$ & $(4)$ \\
\hline SMP1 & -0.13 & -0.03 & 0.04 & \\
& $(0.11)$ & $(0.08)$ & $(0.11)$ & \\
SMP2 & -0.42 & -0.35 & 0.11 & \\
& $(0.51)$ & $(0.36)$ & $(0.34)$ & \\
SMP3 & $-0.15^{*}$ & $-0.13^{* *}$ & -0.02 & \\
& $(0.09)$ & $(0.06)$ & $(0.08)$ & \\
SMP4 & $-0.38^{* * *}$ & $-0.26^{* * *}$ & $-0.16^{* *}$ & \\
& $(0.11)$ & $(0.07)$ & $(0.07)$ & $-0.25^{* * *}$ \\
SMPall & & & & $(0.08)$ \\
& & & & \\
industries & 23 & 23 & 23 & 23 \\
years & $1990-91$, & $1990-2000$ & $1990-91$, & $1990-91$, \\
& $1996-2000$ & & $1996-2000$ & $1996-2000$ \\
\hline$R^{2}$ & 0.95 & 0.94 & 0.97 & 0.95 \\
observations & 829 & 1329 & 829 & 829 \\
\hline
\end{tabular}

Notes: Number of firms is from Eurostat, and SMP measures are from Buigues, Ilzkovitz, and Lebrun (1990) and Eurostat. Columns 1, 2, and 4 use fixed year and countryindustry effects, while Column 3 uses fixed country-year and country-industry fixed effects. Number of firms is logged, and robust standard errors are in parentheses. ${ }^{* * *},{ }^{* *}$, and ${ }^{*}$ refer to one, five, and ten percent levels of significance.

Column 1 of Table 2 reports the results of a regression which includes only observations before 1992 and on or after 1996. The use of these years removes any ambiguity about when the SMP reforms were actually implemented. At first glance, the results seem mixed. Although the point estimates on each SMP variable are all negative, only the coefficient on SMP4 is significantly different from zero (at a 1 percent level of significance). But Griffith, Harrison, 
and Simpson (2010) report that only industries in SMP4 responded to reforms with lower markups across all specifications (their results for SMP1 and SMP3 industries are insignificant, while their results for SMP2 are mixed). The results in Column 1 therefore suggest that effective product market reforms reduce the number of firms, consistent with the cross-country relationship between barriers to competition and the number of firms in the previous section. Column 2 reports the results of the same regression, but using all years from 1990-2000. The results are similarly negative, and the coefficient on SMP3 in this specification is significant. In Column 3 I repeat the benchmark regression from Column 1 using fixed country-year effects. This effectively attributes a portion of the effect of SMP on affected countries to country-specific factors unrelated to SMP, lowering the point estimates on the SMP variables. Column 4 reports the results of a regression on SMPall, a variable that aggregates all of the SMP variables. The estimated coefficient is similar to those in Columns 1 and 2, and remains statistically significant.

Taken together, the evidence from cross-country data in Section 2.1 and from panel data in this section strongly suggest that the number of firms in an industry drops when barriers to competition are reduced.

\section{Model}

In this section I extend a standard model of free entry and endogenous markups to allow for multi-product firms. I show that by modeling barriers to competition as a higher fixed cost of entering a product market, the model can generate all of the empirical relationships discussed earlier. Consider a static economy where a representative final-good firm uses a variety of imperfectly substitutable inputs from each of a continuum of product markets (of measure one) to produce the final consumption good, which also serves as the numéraire. There is a stand-in household endowed with a continuum of members (of measure one), each supplying one unit of labor. There are a large number of identical potential intermediate firms, each of which 
may choose to pay a fixed cost to become a producer. Upon entry firms decide how many products to introduce (i.e., how many product markets to enter) and how much to invest in the quality of each product. I study the decentralized equilibrium of the economy in which firms take the wage, the size of each product market, and the behavior of rival firms as given, and free entry ensures the value of entry is driven to zero. I then consider how barriers to market entry affect the number of firms, the number of products, markups, quality investment, and aggregate output. I begin by describing the environment in more detail.

\subsection{Environment}

There is a continuum of identical consumers of measure one, each supplying one unit of labor to intermediate firms. I assume consumers only value consumption.

The market for final output is perfectly competitive, with a representative firm using inputs from intermediate firms to produce output according to the following production function;

$$
Y=\exp \left(\frac{\sigma}{\sigma-1} \int_{0}^{1} \log \left[\sum_{n=1}^{N_{m}}\left(A_{n m} y_{n m}\right)^{\frac{\sigma-1}{\sigma}}\right] d m\right)
$$

where $m$ indexes a continuum of product markets of measure one, $y_{n m}$ is the quantity demanded of variety $n$ from market $m, N_{m}$ is the number of varieties of input $m$, and $\sigma>1$ is the constant elasticity of substitution between varieties within a product market.

At the beginning of time, any of a large number of identical potential firms can choose to become producers by paying $\left(c_{F}+c_{v} v^{\gamma+1}+c_{A} v A^{\theta}\right) \cdot Y$ units of the final good, where $v$ is the number of product markets entered by a firm, $A$ is the quality of each product, $c_{i}>0, \forall i \in\{F, v, A\}$, $\gamma>0, \theta>1$, and all costs scale up with aggregate output. ${ }^{8}$ Given the finite number of

\footnotetext{
${ }^{8}$ I take it for granted here that a firm will choose the same quality $A$ for each of its products. That all costs scale up with aggregate output is consistent with Bollard, Klenow, and Li (2014), who argue using time-series data that fixed costs scale up with secular development. If population were not normalized to one, I would need to make these costs scale up with output per capita (or the real wage).
} 
competing varieties in each market, firms will choose to introduce only one product per market. That the marginal cost of entering a product market is increasing in the number of markets entered helps to ensure that the number of products per firm is pinned down in equilibrium. Once investment and market-entry decisions are made, firms produce output one-to-one using labor.

\subsection{Equilibrium}

I focus on the decentralized equilibrium of the economy in which producers in each product market take the wage and the behavior of their rivals as given, and choose their demand for labor to maximize profits. Each entrant chooses how many markets to enter and how much to invest in the quality of each product, taking other firms' choices of $v, A$, and labor as given. Potential entrants enter if the value of doing so is non-negative. Given my assumptions all firms behave identically, choosing the same number of markets to enter, the same quality for each product, and the same demand for labor. As such, a decentralized equilibrium is defined as a (common) price for each variety $P$, labor demand for each variety $\ell$, profits per variety $\pi$, quality $A$, a number of varieties per market $N$, a number of products per firm $v$, a real wage $w$, and aggregate output $Y$, such that the above conditions hold, the market for labor clears, and the market for intermediate varieties clears.

The first order conditions for the final-good firm's problem imply the following inverted demand function for variety $n$ in market $m$;

$$
P_{n m}=Y \frac{A_{n m}^{\frac{\sigma-1}{\sigma}} y_{n m}^{-\frac{1}{\sigma}}}{\sum_{n^{\prime}=1}^{N_{m}}\left(A_{n^{\prime} m} y_{n^{\prime} m}\right)^{\frac{\sigma-1}{\sigma}}} .
$$


Operating profits for firm $n$ in market $m$ are;

$$
\pi_{n m}=P_{n m} y_{n m}-w y_{n m}
$$

or

$$
\pi_{n m}=Y \frac{\left(A_{n m} y_{n m}\right)^{\frac{\sigma-1}{\sigma}}}{\left(A_{n m} y_{n m}\right)^{\frac{\sigma-1}{\sigma}}+\left(N_{m}-1\right)\left(\bar{A}_{m} \bar{y}_{m}\right)^{\frac{\sigma-1}{\sigma}}}-w y_{n m}
$$

where $\bar{A}_{m}$ denotes the quality of variety $n$ 's competitors in market $m$ (which are identical in equilibrium) and $\bar{y}_{m}$ is the quantity produced (or labor demanded) by competitors. Maximizing (4) with respect to labor $y_{n m}$ while taking the labor decisions of rival firms as given yields the following first order condition;

$$
\frac{w}{Y}\left(\frac{\sigma}{\sigma-1}\right)=\frac{A_{n m}^{\frac{\sigma-1}{\sigma}}\left(y_{n m}^{*}\right)^{-\frac{1}{\sigma}}\left(N_{m}-1\right)\left(\bar{A}_{m} \bar{y}_{m}\right)^{\frac{\sigma-1}{\sigma}}}{\left[\left(A_{n m} y_{n m}^{*}\right)^{\frac{\sigma-1}{\sigma}}+\left(N_{m}-1\right)\left(\bar{A}_{m} \bar{y}_{m}\right)^{\frac{\sigma-1}{\sigma}}\right]^{2}},
$$

where $y_{n m}^{*}$ is firm $n$ 's optimal demand for labor given $A_{n m}, \bar{A}_{m}, \bar{y}_{m}, N_{m}, w$, and $Y$. By taking into account the fact that qualities and quantities are identical across competitors and markets in equilibrium, condition (5) can be used to express equilibrium output per variety $\bar{y}$ and operating profits per variety $\bar{\pi}$ as functions of $N, w$, and $Y$;

$$
\begin{gathered}
\bar{y}=\frac{Y}{w}\left(\frac{\sigma-1}{\sigma}\right)\left(\frac{N-1}{N^{2}}\right), \\
\bar{\pi}=\frac{Y(N+\sigma-1)}{\sigma N^{2}} .
\end{gathered}
$$

Together with equation (6), labor- and goods-market clearing imply the following expressions for aggregate output and the real wage;

$$
\begin{gathered}
Y=N^{\frac{1}{\sigma-1}} A \\
w=N^{\frac{1}{\sigma-1}} A\left(\frac{\sigma-1}{\sigma}\right)\left(\frac{N-1}{N}\right) .
\end{gathered}
$$


Firms choose $A$ for each product to maximize operating profits less the cost of $A$, taking into account how optimal labor demand depends on $A$. Firm $n$ 's optimal choice of $A$ satisfies;

$$
\theta c_{A} A_{n m}^{\theta-1} Y=\frac{\partial \pi_{n m}^{*}}{\partial A_{n m}}=\frac{Y}{\bar{A}}\left(\frac{\sigma-1}{\sigma}\right)\left(\frac{N-1}{N^{2}}\right)\left(1+\bar{A} N \frac{\partial y_{n m}^{*}}{\partial A_{n m}}\right)-w \frac{\partial y_{n m}^{*}}{\partial A_{n m}}
$$

where $\partial y_{n m}^{*} / \partial A_{n m}$ can be obtained by fully differentiating condition (5) with respect to $A_{n m}$;

$$
\frac{\partial y_{n m}^{*}}{\partial A_{n m}}=\frac{(\sigma-1)(N-2)}{\bar{A} N[2(\sigma-1)+N]} .
$$

Using equations (9) through (11), optimal quality investment per product can now be expressed as;

$$
c_{A} A^{\theta} Y=\frac{Y}{\theta}\left(\frac{\sigma-1}{\sigma}\right)\left(\frac{N-1}{N^{2}}\right) .
$$

When deciding how many markets to enter, firms maximize profits by equating the marginal cost of entering a market to the marginal benefit;

$$
(\gamma+1) c_{v} v^{\gamma} Y+c_{A} A^{\theta} Y=\bar{\pi}
$$

Combining equations (7), (12), and (13) the optimal number of products/markets per firm $(v)$ must satisfy the following condition;

$$
c_{v} v^{\gamma} Y=\frac{Y[N(\theta+\sigma-1)+(\theta+1)(\sigma-1)]}{(\gamma+1) \theta \sigma N^{2}} .
$$

Finally, free entry ensures that the value of forming a firm is equal to zero;

$$
c_{F} Y=v\left(\pi-c_{v} v^{\gamma} Y-c_{A} A^{\theta} Y\right)
$$

or

$$
c_{F}=\frac{v \gamma[N(\theta+\sigma-1)+(\theta+1)(\sigma-1)]}{(\gamma+1) \theta \sigma N^{2}} .
$$


The equilibrium number of products per market $N$, products per firm $v$, and product quality $A$ can now be characterized by the following three expressions;

$$
\begin{gathered}
\text { optimal quality: } \quad A=\left[\frac{\sigma-1}{c_{A} \theta \sigma}\left(\frac{N-1}{N^{2}}\right)\right]^{\frac{1}{\theta}}, \\
\text { optimal markets per firm: } \quad c_{v} v^{\gamma+1}=v \frac{N(\theta+\sigma-1)+(\theta+1)(\sigma-1)}{(\gamma+1) \theta \sigma N^{2}}, \\
\text { free entry: } \quad c_{F}=\gamma c_{v} v^{\gamma+1} .
\end{gathered}
$$

All other variables of interest can be expressed as functions of $N$, $v$, and $A$.

\subsection{Results}

Here I examine how the equilibrium of the economy depends on a number of exogenous variables. I start by discussing the effects of higher barriers to competition, interpreted here as an increase in the cost of entering a product market $c_{v}$.

\subsubsection{Product Market Regulation}

Equation (19) shows that higher barriers to market entry (higher $c_{v}$ ) leads to fewer markets entered by firms and thus fewer products per firm $v$. For a given number of firms this necessarily means fewer competitors per market $N$, and equation (18) shows that $N$ is indeed lower in equilibrium. Each firm's markup over marginal cost $P / w$ is equal to;

$$
\frac{P}{w}=\frac{P}{w} \cdot \frac{N}{N} \cdot \frac{y}{y}=\frac{Y}{w N y} .
$$


With population normalized to one, $y=1 / N$. Using expressions (8) and (9) for aggregate output $Y$ and the real wage $w$, each firm's markup is therefore;

$$
\frac{P}{w}=\frac{Y}{w}=\left(\frac{\sigma}{\sigma-1}\right)\left(\frac{N}{N-1}\right) .
$$

Clearly markups are decreasing in $N$, which means barriers to market entry must increase markups, consistent with the empirical literature examining regulation and markups.

The number of firms in the economy is equal to the total number of products divided by the number of products per firm. To see how the number of firms is affected by barriers to market entry, I combine equations (18) and (19) to obtain the following expression for the number of firms;

$$
\begin{gathered}
\text { \# Firms }=\frac{N}{v}=\Delta \cdot \frac{N(\theta+\sigma-1)+(\theta+1)(\sigma-1)}{N}, \\
\Delta \equiv \frac{\gamma}{c_{F}(\gamma+1) \theta \sigma},
\end{gathered}
$$

where $\Delta$ is independent of $c_{v}$. Given that $N$ is decreasing in $c_{v}$, the number of firms in the economy is clearly increasing in $c_{v}$. The intuition here is fairly straightforward. For a given number of firms, a decrease in $v$ implies a decrease in $N$, which in turn implies both higher markups and higher market shares for each product. This increases the value of forming a firm, which encourages more firms. It is important to note that without both multi-product firms and endogenous markups, the number of firms would not increase. If firms were constrained to produce only one product, then higher fixed costs would necessarily decrease the number of firms ( $N$ in this case) in order to maintain free entry. If markups were fixed (for example, if there were a large number of firms within each market), then higher barriers to market entry would decrease $v$ but leave the number of firms unchanged. In this last case, the drop in firm profits due to the lower number of markets per firm would be exactly offset by the increase in market share due to fewer competitors in each market. The higher markups generated by barriers to market entry in the present model are necessary to encourage more firms in equilibrium. 
Equation (17) shows that product quality $A$ is decreasing in $N$, and therefore increasing in $c_{v}$. As is standard in models with both endogenous markups and endogenous entry, the higher markups generated by barriers to market entry increase the marginal return to investment in quality, thereby encouraging investment. What differs in the present model relative to others in the literature is that product quality need not move in tandem with quality investment per firm. In particular, while product quality rises with barriers to market entry, the number of products per firm decreases. From equations (8), (12), (14), and (17), firm-level investment in quality is equal to;

$$
v \cdot c_{A} A^{\theta} Y=v \frac{Y}{\theta}\left(\frac{\sigma-1}{\sigma}\right)\left(\frac{N-1}{N^{2}}\right),
$$

or

$$
\begin{aligned}
v \cdot c_{A} A^{\theta} Y & =\Psi \cdot \frac{N^{\frac{1}{\sigma-1}-\frac{2}{\theta}}(N-1)^{\frac{\theta+1}{\theta}}}{N(\theta+\sigma-1)+(\theta+1)(\sigma-1)}, \\
\Psi & \equiv \frac{c_{F}(\gamma+1)}{\gamma}\left(\frac{(\sigma-1)^{\theta+1}}{c_{A} \theta \sigma}\right)^{\frac{1}{\theta}}
\end{aligned}
$$

where $\Psi$ is independent of $c_{v}$. To see how firm-level quality investment depends on $c_{v}$, I take the derivative of equation (24) with respect to $N$;

$$
\begin{gathered}
\frac{\partial\left(v \cdot c_{A} A^{\theta} Y\right)}{\partial N}=\Psi \cdot \Phi \cdot\left(\frac{1}{\sigma-1}-\frac{2}{\theta}\right)(N-1) \theta[N(\theta+\sigma-1)+(\theta+1)(\sigma-1)] \\
+\Psi \cdot \Phi \cdot\left(N^{2}(\theta+\sigma-1)+N\left[\sigma \theta^{2}+3 \theta(\sigma-1)+1\right]\right) \\
\Phi \equiv \frac{N^{\frac{1}{\sigma-1}-\frac{2}{\theta}-1}(N-1)^{\frac{1}{\theta}}}{\theta[N(\theta+\sigma-1)+(\theta+1)(\sigma-1)]^{2}} .
\end{gathered}
$$

If $\theta>2(\sigma-1)$ then the increase in product-level quality is not large enough to offset the drop in the number of products per firm, so that firm-level quality investment is monotonically decreasing in $c_{v}$. But if $\theta$ is low enough (relative to $\sigma$ ), then firm-level investment can exhibit an inverted-U relationship with $c_{v}$. In this second case, product quality reacts strongly to increasing markups when markups are initially low, offsetting the drop in the number of products per firm $v$. But as markups continue to rise further, the drop in $v$ dominates and drags firm- 
level investment down. To the extent that differences in markups across equilibria are driven by differences in $c_{v}$, markups and quality investment per firm will therefore exhibit either a negative or inverted-U relationship.

I finally turn to the share of aggregate output invested in product quality. This object is equal to;

$$
N c_{A} A^{\theta}=\left(\frac{\sigma-1}{\theta \sigma}\right)\left(\frac{N-1}{N}\right) .
$$

The aggregate quality investment share is clearly increasing in $N$, and therefore decreasing in markups and barriers to market entry. This result holds even if firm-level investment is increasing with barriers to entry.

That the number of firms in the economy increases with barriers to market entry is consistent with the data presented in Section 2. And the increase in markups that accompanies higher barriers is consistent with Griffith and Harrison (2004), Griffith, Harrison, and Simpson (2010), and Aghion et al. (2005), among others. What about investment in product quality? Several papers have documented how firm-level innovation is higher when markups or market entry barriers are lower, for example Nickell (1996), Blundell, Griffith, and Van Reenen (1999), and Dutz and Hayri (2000). Of particular relevance are Aghion et al. (2005) and Aghion, Braun, and Fedderke (2008), who show that aggregate innovation is decreasing with markups, even when firm-level innovation exhibits an inverted-U relationship with markups. Systematic evidence on product-level quality and the number of products per firm is scant, due in large part to the absence of good product-level data until very recently. I address this in Section 5.

Given the opposing effects of market entry barriers on quality $A$ and the number of competitors per market $N$, equation (8) suggests an ambiguous relationship between aggregate output and barriers. Equations (8) and (12) can be used to express aggregate output solely as a function of $N$;

$$
Y=\left(\frac{\sigma-1}{c_{A} \theta \sigma}\right)^{\frac{1}{\theta}} N^{\frac{1}{\sigma-1}-\frac{2}{\theta}}(N-1)^{\frac{1}{\theta}}
$$


Equation (27) shows that market entry barriers can increase aggregate output if $\sigma$ is high and $\theta$ is low, but will decrease aggregate output otherwise.

To see how entry barriers affect consumption, note that with free entry, the aggregate costs of firm formation, product introduction, and quality investment together must be equal to the fraction of aggregate output retained as operating profits (rather than paid to labor). What is left, consumption, must then be equal to the aggregate wage bill $w$. Equations (9) and (12) can therefore be used to express consumption (or alternatively, the wage) solely as a function of $N$;

$$
C=\left(\frac{\sigma-1}{c_{A} \theta \sigma}\right)^{\frac{1}{\theta}}\left(\frac{\sigma-1}{\sigma}\right) N^{\frac{1}{\sigma-1}-\frac{1}{\theta}}\left(\frac{N-1}{N}\right)^{\frac{\theta+1}{\theta}} .
$$

Similar to the case of aggregate output, entry barriers decrease consumption if $\sigma$ is not too high or $\theta$ is not too low. Entry barriers are less likely to increase consumption than aggregate output, however, in the sense that $\sigma$ must be even higher and $\theta$ even lower. This follows from the fact that increasing markups imply a smaller share of aggregate output allocated to consumption.

\subsubsection{Other}

A tax on quality investment (i.e., an increase in $c_{A}$ ) leads to a decrease in quality $A$, from equation (17). Since the resulting drop in aggregate output reduces both profits and the absolute level of quality investment by the same proportion, the values of both forming a firm and entering a market do not change. As a result, $v, N$, markups, and the number of firms are left unchanged.

It is clear from equations (17) through (19) that an increase in the cost of forming a firm $c_{F}$, a common way of modeling product market regulation, leads to an increase in the number of products per firm $v$, a decrease in $N$, an increase in markups, and an increase in quality $A$. And given the negative relationship between $c_{F}$ and $N$, equation (26) shows that the share of aggregate output invested in quality is decreasing in $c_{F}$. Each of these results (except with 
respect to $v$ ) are consistent with the empirical literature on market entry barriers. But equation (22) shows that an increase in $c_{F}$ also leads to an decrease in the number of firms, in contrast to the positive relationship documented in Section 2. Given that an increase in the cost of forming a firm increases both markups and the number of products per firm, the evidence I document in Section 5 also suggests that the empirical relationship between markups and the number of products per firm across countries is not driven by variation in $c_{F}$.

\section{Quantitative Analysis}

In this section I quantify the impact on an economy of higher barriers to market entry. A quantitative analysis is especially useful here given the ambiguity associated with the theoretical effects of barriers on consumption and output in Section 3. Quantifying the impact of a hypothetical increase in barriers requires values for several parameters, including $\gamma$, which governs how quickly costs increase with the number of products introduced. A value for $\gamma$ is difficult to obtain without detailed firm-product-level data, but it turns out that the implied differences in aggregate productivity and consumption driven by differences in the observed barriers to competition documented by the OECD's PMR dataset can be derived using just three targets and one empirical cross-country relationship. The required targets are the elasticity of substitution between varieties, the average markup in a benchmark economy, and the elasticity of firm revenue with respect to quality investment. I use a value for $\sigma$ equal to 6.5 , which is the elasticity of substitution between varieties suggested by Imbs and Méjean (2015) as appropriate for one-sector models (where all products face the same elasticity). I use the U.S. as my benchmark, and target a markup of 1.26 from Christopoulou and Vermeulen (2008). ${ }^{9}$ Letting $\mu$ denote the benchmark markup, equation (21) shows the benchmark number of competing

\footnotetext{
${ }^{9}$ Christopoulou and Vermeulen estimate markups for a number of manufacturing sectors in the U.S. for the period 1993-2004 using the EU Klems database, and report the weighted (by gross output) average across sectors.
} 
firms per market $N$ is equal to;

$$
N=\frac{\mu(\sigma-1)}{\mu(\sigma-1)-\sigma} .
$$

A $\mu$ of 1.26 implies a number of firms per market $N$ equal to 16 . I target an elasticity of revenue with respect to quality investment of 0.08 , which is the average R\&D elasticity of output reported by Hall, Mairesse, and Mohnen (2010). In Appendix A.1 I show that this elasticity in the model is equal to;

$$
\frac{(\sigma-1)(N-1)}{\theta[2(\sigma-1)+N]} .
$$

Using the obtained values for $\sigma$ and $N$, the above expression suggests a value for $\theta$ of 38.2.

The required empirical relationship for this exercise is that between market entry barriers and the number of firms. Let primed variables indicate those in an economy where market entry barriers are high relative to those in the benchmark economy. From equation (22) the factor difference in the number of firms driven by different entry barriers is;

$$
\frac{\# \text { Firms }^{\prime}}{\# \text { Firms }}=\left(\frac{N}{N^{\prime}}\right) \frac{N^{\prime}(\theta+\sigma-1)+(\theta+1)(\sigma-1)}{N(\theta+\sigma-1)+(\theta+1)(\sigma-1)} .
$$

Given values for $\sigma, N, \theta$, and the factor difference in the number of firms, equation (30) can be used to predict the number of firms per market $N^{\prime}$ in an economy with higher barriers to entry. With values for each of these parameters and variables, equations (27) and (28) can then be used to quantify the differences in aggregate productivity and consumption driven by the cross-country differences in market entry barriers documented by OECD;

$$
\begin{gathered}
\frac{Y^{\prime}}{Y}=\left(\frac{N^{\prime}}{N}\right)^{\frac{1}{\sigma-1}-\frac{2}{\theta}}\left(\frac{N^{\prime}-1}{N-1}\right)^{\frac{1}{\theta}}, \\
\frac{C^{\prime}}{C}=\frac{Y^{\prime}}{Y}\left(\frac{N^{\prime}-1}{N-1}\right)\left(\frac{N}{N^{\prime}}\right) .
\end{gathered}
$$

To find the factor difference in the number of firms associated with higher market entry barriers in the data, I use the elasticity of the number of firms with respect to market entry barriers 
from Column 3 of Table 1 (0.92). Given this elasticity, the factor change in the number of firms

when the level of product market regulation in the benchmark economy (the level reported for the U.S., 1.11) is increased to a higher level $\left(P M R^{\prime}\right)$ is equal to;

$$
\frac{\# \text { Firms }^{\prime}}{\# \text { Firms }_{U S}}=\left(\frac{P M R^{\prime}}{1.11}\right)^{0.92} \text {. }
$$

Table 3: Quantitative Effects of Market Entry Barriers

\begin{tabular}{lcccccc}
\hline PMR & $\begin{array}{c}\text { Number } \\
\text { of Firms }\end{array}$ & $\begin{array}{c}\text { Products } \\
\text { per Firm }\end{array}$ & $\begin{array}{c}\text { Firm-Level } \\
\text { Investment }\end{array}$ & $\begin{array}{c}\text { Aggregate } \\
\text { Investment }\end{array}$ & $\begin{array}{c}\text { Aggregate } \\
\text { Output }\end{array}$ & Cons. \\
\hline 1.11 (U.S.) & 1 & 1 & 1 & 1 & 1 & 1 \\
1.46 (Australia) & 1.29 & 0.35 & 0.63 & 0.92 & 0.88 & 0.81 \\
1.94 (Korea) & 1.67 & 0.16 & 0.39 & 0.81 & 0.81 & 0.65 \\
2.21 (Greece) & 1.88 & 0.11 & 0.31 & 0.75 & 0.78 & 0.58 \\
2.69 (Russia) & 2.26 & 0.07 & 0.21 & 0.64 & 0.74 & 0.48 \\
3.40 (India) & 2.80 & 0.04 & 0.12 & 0.49 & 0.70 & 0.34 \\
\hline
\end{tabular}

Notes: Columns report equilibrium values of various variables when market entry costs are raised enough to match each country's PMR score. PMR data is from the OECD's Indicators of Product Market Regulation. In column headers, 'investment' refers to quality investment. All results are reported relative to the benchmark U.S. economy.

Table 3 reports the model's predictions of how various variables change relative to the benchmark economy when market entry barriers are increased. For example, barriers high enough to increase the PMR score from the U.S. level to that of Australia increase the number of firms by 29 percent, while decreasing the number of products per firm by 65 percent. Firm-level quality investment decreases by 37 percent, but aggregate quality investment (as a share of output) decreases by only 8 percent. Aggregate output decreases by 12 percent, but consumption drops by 19 percent as a larger fraction of output is invested in entry. The highest value reported in the PMR data is for India. The model suggests that the higher barriers to competition in India are alone enough to increase the number of firms by a factor of 2.8 , decrease aggregate output by 30 percent, and reduce consumption by a substantial 66 percent. 
Some general comments about these results are in order. First, market entry barriers alone can not explain the large cross-country differences in the number of firms per worker. But this is consistent with the fact that other factors have been identified that contribute to these differences. Second, the inverted-U relationship between competition and firm-level quality investment that is possible in Section 3 does not appear in Table 3, as firm-level investment is strictly decreasing in entry barriers. It is worth noting, though, that if the model were extended to allow for multiple sectors characterized by different values for $\theta$, then the inverted$\mathrm{U}$ relationship could still emerge in sectors with low values for $\theta$. Third, there is some variation in the empirical literature in estimates for both average markups and the $R \& D$ elasticity of output. In Table 3 I recalibrate the model using higher and lower targets, and report the results for the highest PMR score in the data, 3.40. The quantitative results are remarkably robust to moderate changes in these targets.

Table 4: Robustness: Different Targets

\begin{tabular}{|c|c|c|c|c|c|c|}
\hline PMR & $\begin{array}{l}\text { Number } \\
\text { of Firms }\end{array}$ & $\begin{array}{l}\text { Products } \\
\text { per Firm }\end{array}$ & $\begin{array}{l}\text { Firm-Level } \\
\text { Investment }\end{array}$ & $\begin{array}{l}\text { Aggregate } \\
\text { Investment }\end{array}$ & $\begin{array}{c}\text { Aggregate } \\
\text { Output }\end{array}$ & Cons. \\
\hline \multicolumn{7}{|c|}{ benchmark } \\
\hline \multicolumn{7}{|c|}{ markup in U.S. $=1.26, \quad$ RESD elasticity $=0.08$} \\
\hline 3.40 & 2.80 & 0.04 & 0.12 & 0.49 & 0.70 & 0.34 \\
\hline \multicolumn{7}{|c|}{ markup in U.S. $=1.30, \quad$ RESD elasticity $=0.08$} \\
\hline 3.40 & 2.80 & 0.05 & 0.11 & 0.41 & 0.73 & 0.30 \\
\hline \multicolumn{7}{|c|}{ markup in U.S. $=1.22, \quad$ RESD elasticity $=0.08$} \\
\hline 3.40 & 2.80 & 0.03 & 0.13 & 0.57 & 0.64 & 0.37 \\
\hline \multicolumn{7}{|c|}{ markup in U.S. $=1.26, \quad$ RED elasticity $=0.04$} \\
\hline 3.40 & 2.80 & 0.04 & 0.13 & 0.51 & 0.69 & 0.35 \\
\hline \multicolumn{7}{|c|}{ markup in U.S. $=1.26, \quad R E D$ elasticity $=0.12$} \\
\hline 3.40 & 2.80 & 0.04 & 0.12 & 0.47 & 0.71 & 0.33 \\
\hline
\end{tabular}

Notes: Columns report equilibrium values of various variables when market entry costs are raised enough to match a PMR score of 3.40. To generate the values of each row, the model is recalibrated to match a different markup or a different R\&D elasticity. In column headers, 'investment' refers to quality investment. All results are reported relative to the benchmark U.S. economy. 


\section{Products per Firm and Product Quality}

The model developed in Section 3 generates testable predictions for the effect of market entry barriers on both the number of products per firm and product quality. In particular, the model predicts that higher barriers to market entry should induce a lower number of products per firm and higher product quality. In this section I use data from multiple sources to test these predictions.

\subsection{Barriers and Products per Firm}

For a measure of products per firm I use data from the World Bank's Enterprise Surveys (ES). Between 2002 and 2006, establishment- and firm-level data was collected though face-to-face surveys from mostly low- and middle-income countries. The ES dataset contains standardized information about sales, intermediate purchases, inputs, and a host of other variables. Manufacturing firms are categorized into fifteen industries, and efforts have been made to make these samples representative of the population of firms with at least five employees. ${ }^{10}$ Most importantly for my purposes, firms in a (smaller) number of countries were asked about their total number of product lines. Unfortunately, only five countries with product data are also present in the OECD's Product Market Regulation dataset. But given the availability of other firm-level data, I can at least test the relationship between the number of products per firm and average markups across countries. For my measure of markups, I calculate a simple ratio of value added over a firm's wage bill and use the mean of this statistic across all firms within a country-industry. ${ }^{11}$ I neglect to include any measure of capital here because some countries and many firms within each country do not report capital. Including only firms that report capital would significantly reduce the total number of usable firms and drastically reduce the number of usable countries. Although neglecting capital will lead to a biased measure of the level of

\footnotetext{
${ }^{10}$ For more information about the Enterprise Surveys data, see enterprisesurveys.org.

${ }^{11}$ The wage bill in these calculations includes both wages and benefits paid for by a firm.
} 
markups, this bias should remain constant across countries (in proportion to the markup itself).

Before estimating the relationship between products per firm and average markups, I first ensure that my cross-country measure of markups behaves consistently with other measures in the empirical literature. The first column of Table 5 reports the results of an OLS regression of markups on the PMR Index, controlling only for industry. Consistent with both the existing empirical literature and the model from Section 3 (as well as other models with endogenous markups), markups are higher in countries with higher barriers to competition. Column 2 shows that this result does not change when including the ten control variables from Section 2. In Column 3 I report the results of a weighted least squares regression, where each countryindustry observation is weighted by the number of firm-level observations used to calculate the average markup. The estimate on PMR is again significant, though much greater in magnitude.

\section{Table 5: Markups And Products Per Firm}

\begin{tabular}{lllllll}
\hline dependent variables: & \multicolumn{3}{c}{ markups } & \multicolumn{5}{c}{ products per firm } \\
& $(1)$ & $(2)$ & $(3)$ & $(4)$ & $(5)$ & $(6)$ \\
\hline PMR & $1.60^{* * *}$ & $1.64^{* * *}$ & $4.98^{* * *}$ & & & \\
& $(0.30)$ & $(0.60)$ & $(1.59)$ & & & \\
Markups & & & & $-0.24^{* * *}$ & $-0.23^{* * *}$ & $-0.25^{* * *}$ \\
& & & & $(0.08)$ & $(0.08)$ & $(0.09)$ \\
& & & & & & \\
Controls & No & Yes & Yes & No & Yes & Yes \\
Industry Dummies & Yes & Yes & Yes & Yes & Yes & Yes \\
& & & & & & \\
\hline$R^{2}$ & 0.25 & 0.41 & 0.55 & 0.13 & 0.30 & 0.42 \\
observations & 204 & 204 & 204 & 192 & 192 & 192 \\
countries & 21 & 21 & 21 & 24 & 24 & 24 \\
industries & 14 & 14 & 14 & 14 & 14 & 14 \\
\hline
\end{tabular}

Notes: PMR is from the OECD's Indicators of Product Market Regulation. Markups and products per firm are from the World Bank's Enterprise Surveys dataset. All controls are from the World Bank's Doing Business dataset. All variables are logged, and robust standard errors are in parentheses. ${ }^{* * *}$ refers to a one percent level of significance.

Column 4 from Table 5 reports the results of an OLS regression of products per firm on average markups, and Column 5 reports very similar results when the control variables from Section 
2 are included. Consistent with the model, these results suggest that firms in countries with more restrictive barriers to competition produce significantly fewer products. Column 6 reports the results of a weighted least squares regression, where each country-industry observation is weighted by the number of firm-level observations used to calculate the average number of products per firm. The estimate on markups is again significant and of similar magnitude.

\subsection{Barriers and Product Quality}

To test the relationship between barriers to competition and average product quality, I use the average number of citations per patent applied for in the U.S. originating from a countryindustry (in the year 2000 or later). Patent and citation data is from the NBER Patent Database, described in Hall, Jaffe, and Trajtenberg (2001). The number of citations to a patent has become a widely-used measure of patent quality, and using only patents applied for in the U.S. helps to control for country-specific patent laws that might affect patenting activity without affecting actual innovation. I continue to control for the Doing Business variables included in the regressions from Tables 1 and 5 . In addition, the strength of patent protection in an originating country could presumably affect innovation and patenting activity. I therefore control for the strength of patent protection using each country's Patent Rights Index value, as constructed and reported in Park (2008). Other factors may still affect which innovations are patented in the U.S., however. In particular, firms in countries far from the U.S. or in countries much poorer than the U.S. may only find it profitable to patent innovations of relatively high quality. I therefore control for GDP per capita and distance from the U.S. ${ }^{12}$ Finally, it must be noted that the validity of using patent quality as a proxy for product quality depends on the (plausible, I believe) assumption that the average number of patents per product does not

\footnotetext{
${ }^{12}$ GDP per capita is in PPP terms, from Penn World Tables v8, described in Feenstra, Inklaar, and Timmer (2015). Distance is equal to the distance in miles from a country's capital city to Washington DC. I also exclude U.S. observations from the analysis, on the presumption that the domestic patenting activity of firms may be different than their patenting activity in a foreign country. Including U.S. observations changes the point estimates on PMR marginally, without changing their statistical significance.
} 
itself depend on the level of product market regulation. If product market regulation somehow encouraged fewer patents per product, then the number of citation-weighted patents per product could still decrease even while the number of citations per patent increased.

Table 6: Product-Market Regulation and Patent Quality

\begin{tabular}{lllll}
\hline dependent variable: & \multicolumn{4}{c}{ citations per patent } \\
& $(1)$ & $(2)$ & $(3)$ & $(4)$ \\
\hline PMR & $-0.16^{* * *}$ & $0.40^{* * *}$ & $0.41^{* * *}$ & $0.46^{* * *}$ \\
& $(0.04)$ & $(0.08)$ & $(0.10)$ & $(0.05)$ \\
Patent Index & & & -0.03 & $0.18^{* * *}$ \\
& & & $(0.12)$ & $(0.05)$ \\
Distance & & & 0.01 & $0.03^{* * *}$ \\
& & & $(0.02)$ & $(0.01)$ \\
GDP per Capita & & & 0.07 & $0.09^{* * *}$ \\
& & & $(0.05)$ & $(0.03)$ \\
Controls & No & Yes & Yes & Yes \\
Industry Dummies & Yes & Yes & Yes & Yes \\
& & & & \\
\hline$R^{2}$ & 0.09 & 0.10 & 0.10 & 0.08 \\
observations & 6552 & 6552 & 6456 & 6456 \\
countries & 45 & 45 & 40 & 40 \\
industries & 419 & 419 & 419 & 419 \\
\hline
\end{tabular}

Notes: Patent and citation data are from the NBER Patent Database, PMR is from the OECD's Indicators of Product Market Regulation, Patent Index is from Park (2008), control variables are from the World Bank's Doing Business dataset, and GDP per capita is from Penn World Tables v8. All estimates from Poisson regressions. Robust standard errors in parentheses. ${ }^{* * *}$ refers to a one percent level of significance.

The first column of Table 5 reports the results of a poisson regression of the average number of citations per patent in 6552 country-industries on the PMR score for 45 countries, using fixed industry effects for 419 industries. The coefficient estimate on PMR is negative and significant, contradicting the prediction of the model developed in Section 3. But Columns 2 and 3 show that the estimate on PMR becomes positive (and still significant) once other country-specific factors are controlled for. This suggests that the control variables included in Columns 2 and 3 (which tend to be negatively correlated with PMR) tend to increase patent quality on average. Column 4 shows the estimate on PMR is slightly higher when observations are weighted by the 
number of patents used to calculate the average number of citations per patent.

\section{Conclusion}

In this paper I provide new evidence suggesting that barriers to competition actually increase the number of firms in an industry, in contrast to all current models of endogenous markups with free entry. I rationalize this finding by extending a standard model to allow for multiproduct firms which face barriers to entering a product market. In this environment, high barriers result in more, smaller firms with fewer products. The model rationalizes another empirical phenomenon that has been difficult to generate in models with free entry - that higher markups due to entry barriers tend to be associated with lower firm-level innovation. By breaking the link between firm-level and product-level innovation, the model is able to produce a novel, intuitive explanation for this empirical phenomenon. While higher markups encourage quality investment for a given product, the lower number of products per firm drags down total firm-level investment. The calibrated model suggests that observed differences in barriers to competition can generate substantial differences in consumption across countries.

Besides the relationship between barriers and the number of firms, the model generates two

previously untested predictions - that barriers to competition should reduce the number of products per firm, and increase the quality of products. Combining data from several different sources, I test each of these predictions and find they are consistent with the evidence. 


\section{A Appendix}

\section{A.1 Elasticity of Revenue with respect to Quality Investment}

Here I derive the elasticity of firm revenue with respect to quality investment. Using equation (3), revenue for firm $n$ in market $m$ is equal to;

$$
P_{n m} y_{n m}=Y \frac{\left(A_{n m} y_{n m}\right)^{\frac{\sigma-1}{\sigma}}}{\sum_{n^{\prime}=1}^{N_{m}}\left(A_{n^{\prime} m} y_{n^{\prime} m}\right)^{\frac{\sigma-1}{\sigma}}}
$$

and the elasticity of revenue with respect to quality investment is;

$$
\frac{\partial\left(P_{n m} y_{n m}\right)}{\partial A_{n m}} \cdot \frac{A_{n m}}{P_{n m} y_{n m}} \cdot\left(\frac{\partial\left(A_{n m}^{\theta}\right)}{\partial A_{n m}}\right)^{-1} \cdot \frac{A_{n m}^{\theta}}{A_{n m}}=\frac{\partial\left(P_{n m} y_{n m}\right)}{\partial A_{n m}} \cdot \frac{A N}{Y \theta}
$$

or

$$
\left(\frac{\sigma-1}{\sigma}\right)\left(\frac{N-1}{\theta N y}\right)\left[y+A \cdot \frac{\partial y_{n m}^{*}}{\partial A_{n m}}\right] .
$$

Using equation (11) for $\partial y_{n m}^{*} / \partial A_{n m}$ and $y=1 / N$, this reduces to;

$$
\frac{(\sigma-1)(N-1)}{\theta[2(\sigma-1)+N]}
$$




\section{References}

[1] Aghion, Philippe, Nick Bloom, Richard Blundell, Rachel Griffith, and Peter Howitt, "Competition and Innovation: An Inverted-U Relationship," Quarterly Journal of Economics, 120 (2005), 701-728.

[2] Aghion, Philippe, Matius Braun, and Johannes Fedderke, "Competition and Productivity Growth in South Africa," Economics of Transition, 16 (2008), 741-768.

[3] Bento, Pedro, "Competition as a Discovery Procedure: Schumpeter Meets Hayek in a Model of Innovation," American Economic Journal: Macroeconomics, 6 (2014),124-152 .

[4] Bento, Pedro and Diego Restuccia, "Misallocation, Establishment Size, and Productivity," Texas A\&3M University Working Paper, 20150801-001 (2015).

[5] Bernard, Andrew B., Stephen J. Redding, and Peter K. Schott, "Multiple-Product Firms and Product Switching," American Economic Review, 100 (2010), 70-97.

[6] Bhattacharya, Dhritiman, Nezih Guner, and Gustavo Ventura, "Distortions, Endogenous Managerial Skills and Productivity Differences," Review of Economic Dynamics, 16 (2013), $11-25$.

[7] Blundell, Richard, Rachel Griffith, and John Van Reenen, "Market Share, Market Value and Innovation in a Panel of British Manufacturing Firms," Review of Economic Studies, 66 (1999), 529-554.

[8] Bollard, Albert, Peter J. Klenow, and Huiyu Li, "Entry Costs Rise with Development," manuscript, (2014).

[9] Buigues, Pierre-André, Fabienne Ilzkovitz, and J.F. Lebrun, "The Impact of the Internal Market by Industrial Sector: The Challenge for Member States," European Economy, Special Issue (1990). 
[10] Carlson, Mark and Kris James, "Branch Banking, Bank Competition, and Financial Stability," Journal of Money, Credit and Banking, 38 (2006), 1293-1328.

[11] Christopoulou, Rebekka and Philip Vermeulen, "Markups in the Euro Area and the US Over the Period 1981-2004: A Comparison of 50 Sectors," Empirical Economics, 42 (2008), 1-25.

[12] Desmet, Klaus and Stephen L. Parente, "Bigger is Better: Market Size, Demand Elasticity, and Innovation" International Economic Review, 51 (2010), 319-333.

[13] Dutz, Mark A. and Aydin Hayri, "Does More Intense Competition Lead to Higher Growth?" Policy Research Working Paper Series, 2320 (2000).

[14] Edmond, Chris, Virgiliu Midrigan, and Daniel Xu, "Competition, Markups and the Gains from International Trade" American Economic Review, 105 (2015) 3183-3221.

[15] Feenstra, Robert C., Robert Inklaar, and Marcel P. Timmer, "The Next Generation of the Penn World Table," American Economic Review, 105 (2015), 3150-3182.

[16] Griffith, Rachel and Rupert Harrison, "The Link Between Product Market Reform and Macro-Economic Performance," European Economy, European Commission, DirectorateGeneral for Economic and Financial Affairs, Economic Papers, 209 (2004).

[17] Griffith, Rachel, Rupert Harrison, and Helen Simpson, "Product Market Reform and Innovation in the EU," Scandinavian Journal of Economics, 112 (2010).

[18] Hall, Bronwyn H., Adam Jaffe, and Manuel Trajtenberg, "The NBER Patent Citations Data File: Lessons, Insights and Methodological Tools," NBER Working Papers, 8498 (2001).

[19] Hall, Bronwyn H., Jacques Mairesse, and Pierre Mohnen, "Measuring the Returns to R\&D," in Handbook of the Economics of Innovation, ed: Bronwyn H. Hall and Nathan Rosenberg, 2 (2010) 733-1256. 
[20] Holmes, Thomas J. and James A. Schmitz, Jr., "Competition and Productivity: A Review of Evidence," Annual Review of Economics, 2 (2010), 619-642.

[21] Hsieh, Chang-Tai and Peter J. Klenow, "The Life Cycle of Plants in India and Mexico," Quarterly Journal of Economics, 129 (2014), 1035-1084.

[22] Imbs, Jean and Isabelle Méjean, "Elasticity Optimism," American Economic Journal: Macroeconomics, 7 (2015), 43-83.

[23] Koske, Isabell, Isabelle Wanner, Rosamaria Bitetti, and Omar Barbiero, "The 2013 Update of the OECD's Database On Product Market Regulation," OECD Economics Department Working Papers, 1200 (2015).

[24] Melitz, Marc J., "The Impact of Trade on Intra-Industry Reallocations and Aggregate Industry Productivity," Econometrica, 71 (2003), 1695-1725.

[25] Melitz, Marc J. and Giancarlo P. Ottaviano, "Market Size, Trade, and Productivity," Review of Economic Studies, 75 (2008), 295-316.

[26] Nickell, Stephen J., "Competition and Corporate Performance," Journal of Political Economy, 104 (1996), 724-746.

[27] Nicoletti, Giuseppe and Stefano Scarpetta, "Regulation, Productivity, and Growth: OECD Evidence," Economic Pollicy, 18 (2003), 9-72.

[28] Notaro, Giovanni, "European Integration and Productivity: Exploring the Gains of the Single Market," London Economics Working Paper, (2002).

[29] Park, Walter G., "International Patent Protection: 1960-2005," Research Policy, 37 (2008), $761-766$.

[30] Peters, Michael, "Heterogeneous Mark-Ups, Growth and Endogenous Misallocation," manuscript, (2013).

[31] Schumpeter, Joseph A., Capitalism, Socialism and Democracy, New York: Harper, (2013). 
[32] Stigler, George J. and Robert A. Sherwin, "The Extent of the Market," Journal of Law and Economics, 28 (1985), 555-585. 